\title{
Myocardial Injury after Noncardiac Surgery and Perioperative Atrial Fibrillation: From Evidence to Clinical Practice
}

Flavia K. Borges, MD, PhD ${ }^{1,2,3}$, Sandra Ofori, MD ${ }^{1,4}$, Maura Marcucci, MD ${ }^{1,2,3,4}$

${ }^{1}$ Anesthesia, Perioperative Medicine, and Surgical Research Unit, Population Health Research Institute, Hamilton, Canada; ${ }^{2}$ Department of Medicine, McMaster University, Hamilton, Canada; ${ }^{3}$ Division of Perioperative Care, Department of Health Research Methods, Evidence, and Impact, McMaster University, Hamilton, Canada; ${ }^{4}$ Health Research Methodology, Department of Health Research Methods, Evidence, and Impact, McMaster University, Hamilton, Canada

Address for correspondence: Maura.Marcucci2@phri.ca

Submitted: November 18, 2020. Accepted: 8 January 2021. Published: March 16, 2021. DOI: 1022374/cjgim.v16iSP1.530.

\begin{abstract}
One in 60 patients who undergo major noncardiac surgery dies within 30 days following surgery. The most common cause is cardiac complications, of which myocardial injury after noncardiac surgery (MINS) and perioperative atrial fibrillation (POAF) are common, affecting about 18 and $11 \%$ of adults, respectively, after noncardiac surgery. Patients who suffer MINS are at a higher risk of death compared to patients without MINS. Similarly, patients who develop POAF are at a higher risk of stroke and death compared to patients who do not. Most patients who suffer MINS are asymptomatic, and its diagnosis is not possible without routine troponin monitoring. Observational studies support the use of statins and aspirin in the management of patients with MINS. The only randomized controlled trial to date that has specifically addressed the management of MINS was the MANAGE trial that demonstrated the efficacy and safety of intermediate dose dabigatran in this population. There are no specific prediction models for POAF and no randomised controlled trial evidence to guide the specific management of POAF. Management guidelines in the acute period follow the management of nonoperative atrial fibrillation. The role of long-term anticoagulation in this population is still uncertain and should be guided by a shared care decision model with the patient, and with consideration of the individual risk for stroke balanced against the risk of bleeding. In this review, we present a case-based approach to the detection, prognosis, and management of MINS and POAF based on the existing evidence.
\end{abstract}

\section{RÉSUMÉ}

Un patient sur 60 qui subit une intervention chirurgicale majeure non cardiaque meurt dans les 30 jours suivant lopération. La cause la plus fréquente est celle des complications cardiaques, dont les lésions myocardiques après une chirurgie non cardiaque (LMCNC) et la fibrillation auriculaire périopératoire (FAPO) sont courantes et touchent respectivement environ 18 et $11 \%$ des adultes après une chirurgie non cardiaque. Les patients présentant des LMCNC sont exposés à un risque plus élevé de décès que les patients qui ne présentent pas de LMCNC. De même, les patients chez qui on voit apparaitre une FAPO ont un risque plus élevé d’accident vasculaire cérébral et de décès que ceux qui ne connaitront pas cette complication. La plupart des patients atteints de LMCNC sont asymptomatiques, et il est impossible détablir un diagnostic sans surveiller régulièrement la 
troponine. Des études d’observation appuient l'utilisation des statines et de l'aspirine dans la prise en charge des patients atteints de LMCNC. À ce jour, le seul essai contrôlé randomisé qui sest penché précisément sur le traitement des LMCNC est lessai MANAGE qui a démontré lefficacité et l'innocuité du dabigatran à dose intermédiaire chez cette population. Il nexiste aucun modèle de prédiction précis pour la FAPO ni aucune donnée probante provenant d'essais contrôlés randomisés pour orienter précisément son traitement. Les lignes directrices concernant la prise en charge au cours de la période aiguë suivent celles de la prise en charge de la fibrillation auriculaire non liée à une opération. Le rôle de lanticoagulation à long terme chez cette population est encore incertain et devrait être guidé par un modèle de prise de décision partagée avec le patient et tenir compte du risque individuel d'accident vasculaire cérébral par rapport à celui d'hémorragie. Dans cette revue, nous présentons une approche fondée sur des cas pour la détection, le pronostic et le traitement des LMCNC et de la FAPO sur la base des données probantes existantes.

\section{Key Learning Points}

- Myocardial injury after noncardiac surgery (MINS) is frequent and is associated with increased 30-day and 1-year mortality and cardiovascular events.

- MINS occurs without symptoms in most of the cases and would remain undetected without routine postoperative troponin monitoring.

- Further risk stratification, secondary cardiovascular prevention, and close follow-up should be considered in patients with MINS.

- Perioperative atrial fibrillation (POAF) complicates many noncardiac surgeries and is associated with in-hospital adverse outcome and increased long-term risk of stroke and mortality.

- Management of POAF includes identification and treatment of triggers, acute rhythm or rate control, assessment of long-term risk of recurrence and cardiometabolic risk, and consideration for long-term oral anticoagulation.

\section{Introduction}

Globally, over 300 million adults undergo noncardiac surgery every year. ${ }^{1}$ Noncardiac surgery can improve patient quality of life and prolong survival. However, perioperative complications are not uncommon. Acute cardiovascular events are among the most frequent complications. ${ }^{2,3}$ They include myocardial injury after noncardiac surgery (MINS) and perioperative atrial fibrillation (POAF). This review offers insights into the management of these complications using a case-based approach.

\section{Myocardial Injury after Noncardiac Surgery: Clinical Scenario}

Ms. A.S. is a 77-year-old female who underwent hip fracture surgery. She had no risk factors for, or a previous history of, cardiovascular disease. Preoperatively, she was independent in all activities of daily living. Intraoperatively, she experienced hypotension with a systolic blood pressure (BP) $<90 \mathrm{mmHg}$ for $15 \mathrm{~min}$. Routine postoperative monitoring showed highsensitivity troponin I (hsTnI) at $64 \mathrm{ng} / \mathrm{L}$ (upper reference limit [URL] $30 \mathrm{ng} / \mathrm{L}$ ) on postoperative day 1 . She had no chest pain or shortness of breath. Her heart rate was 86 beats/min, BP 134/75 was $\mathrm{mmHg}$, and heart and lung sounds were normal.
The electrocardiogram (ECG) was unremarkable. HsTnI peaked at $75 \mathrm{ng} / \mathrm{L}$ the next day. She remained asymptomatic. She was discharged home on aspirin and a statin, with a plan to follow-up with her family physician and surgeon.

One month later, she presented to the emergency department with chest pain. Her BP was 138/78 mmHg, and her heart rate was 72 beats/min. The exam was unremarkable. ECG showed a new left bundle branch block (LBBB). Initial HsTnI was $88 \mathrm{ng} / \mathrm{L}$ and peaked at $1468 \mathrm{ng} / \mathrm{L} 12 \mathrm{~h}$ later. She underwent urgent cardiac catheterization. Left ventriculogram showed preserved left ventricular ejection fraction with no regional wall motion abnormalities but significant 3-vessel coronary artery disease (CAD). She subsequently underwent triple coronary artery bypass graft surgery. She was discharged home in a stable condition on aspirin, an angiotensin-converting-enzyme (ACE) inhibitor, a beta-blocker, and a high-dose statin.

\section{What Is MINS?}

MINS is defined as an acute elevation of troponin due to myocardial ischemia occuring during or within 30 days after noncardiac surgery. MINS includes patients that fulfil the Universal Definition of myocardial infarction (MI), and patients 
with ischemic troponin elevation without any ischemic features (e.g., chest pain or ischemic electrocardiographic findings). ${ }^{5}$ Postoperative troponin elevation due to other nonischemic etiologies (e.g., pulmonary embolism, sepsis) are not considered as MINS.

\section{What Is the Prognostic Impact of MINS?}

MINS is the most common cardiovascular complication after noncardiac surgery. Patients with MINS have a higher 30-day mortality and a higher risk of recurrent short- and long-term cardiovascular complications. ${ }^{5,6}$ A recent systematic review (169 studies and $>530,000$ patients) estimated the incidence of MINS at $18 \% .{ }^{7}$ Compared to patients without MINS, those with MINS had higher mortality, both in hospital (8.1\%, vs $0.4 \%$; relative risk $[\mathrm{RR}] \mathrm{8.3}, 95 \%$ confidence interval $[\mathrm{CI}], 4.2-16.6)$ and at 1 year after surgery (20.6\% vs 5.1\%; RR 4.1, 95\% CI, 3.0-5.6).

\section{What Are the Troponin Thresholds for MINS?}

The Vascular events In noncardiac Surgery patIents cOhort evaluatioN (VISION) study included a representative sample of 40,004 patients undergoing inpatient noncardiac surgery ${ }^{8}$ and was the first study to establish prognostically relevant troponin thresholds for MINS independently associated with death at 30 days. A fourth generation nonhigh-sensitivity troponin $\mathrm{T}$ $(\operatorname{TnT}) \geq 0.03 \mathrm{ng} / \mathrm{mL}$ or a fifth generation high-sensitivity troponin $\mathrm{T}$ (hsTnT) of 20 to $<65 \mathrm{ng} / \mathrm{L}$ with an absolute change of $\geq 5 \mathrm{ng} / \mathrm{L}$ or a hsTnT level $\geq 65 \mathrm{ng} / \mathrm{L}$ were independently associated with 30-day postoperative mortality. ${ }^{5,8}$ VISION substudies have also established optimal hsTnI thresholds for MINS. A hsTnI $\geq 60$ ng/L (ARCHITECT STAT Abbot assay) ${ }^{9}$ and a hsTnI $\geq 75 \mathrm{ng} / \mathrm{L}$ (Siemens Healthineers ADVIA Centaur Assay $)^{10}$ are associated with major cardiovascular events 30 days after noncardiac surgery. For other troponin assays, physicians should consider any elevation above the 99th percentile URL as the threshold for MINS. ${ }^{5}$

Importantly, the VISION Study demonstrated that the higher the postoperative troponin peak, the higher the 30-day mortality. Patients with a peak postoperative hsTnT levels of 65 to $<1000 \mathrm{ng} / \mathrm{L}$ had 30 -day mortality rates of $9.1 \%$, and patients with hsTnT levels of $\geq 1000 \mathrm{ng} / \mathrm{L}$ had $29.6 \% 30$-day mortality. ${ }^{8}$

\section{Which Patients Should be Monitored for MINS?}

Patients with MINS are more likely to be older, male, and have cardiovascular risk factors. ${ }^{7,11-13}$ The Canadian Cardiovascular Society (CCS) Guidelines ${ }^{14}$ recommend that patients undergoing noncardiac surgery with a Revised Cardiac Risk Index score (RCRI) $\geq 1,{ }^{15}$ age $\geq 65$ years or $45-64$ years with significant cardiovascular disease, or patients with elevated preoperative $\mathrm{N}$-terminal prohormone brain natriuretic peptide (NT-proBNP $\geq 300 \mathrm{ng} / \mathrm{L}$ ) or brain natriuretic peptide (BNP $\geq 92 \mathrm{mg} / \mathrm{L}$ ) be routinely monitored for MINS. Recent data from the VISION cohort demonstrated that among 10,402 patients, compared with a reference preoperative NT-proBNP $<100 \mathrm{pg} / \mathrm{mL}$, adjusted hazard ratios [aHR] for the occurrence of the primary outcome (i.e., vascular death or MINS) within 30 days after noncardiac surgery were 2.27 (95\% CI, 1.90 to 2.70) for NT-proBNP of 100 to $<200 \mathrm{pg} / \mathrm{mL}, 3.63$ (CI, 3.13 to 4.21 ) for NT-proBNP of 200 to $<1500 \mathrm{pg} / \mathrm{mL}$, and 5.82 (CI, 4.81 to 7.05 ) for NT-proBNP $\geq 1500$ $\mathrm{pg} / \mathrm{mL}$. The associated incidence of the primary outcome was $12.3,20.8$, and $37.5 \%$, respectively. ${ }^{16}$ The European Society of Cardiology (ESC) guidelines suggest biomarker measurements in high-risk patients, including NT-proBNP for prognosis assessment and cardiac troponin both before and $48-72 \mathrm{~h}$ after major surgery. ${ }^{17,18}$ The most recent Universal definition of MI statement also recommends perioperative troponin surveillance for high-risk individuals undergoing noncardiac surgery. ${ }^{19}$

In the VISION study, $38.2 \%$ of patients who had MINS experienced this on the day of surgery, $39.4 \%$ on postoperative day $1,16.5 \%$ on postoperative day 2 , and only $5.3 \%$ on postoperative day $3 .^{8}$ Importantly, in up to $93 \%$ of cases, the index MINS event is asymptomatic. ${ }^{8}$ After surgery, patients are commonly on analgesics that can mask ischemic symptoms. Compared to patients without MINS, patients who have MINS, without or with ischemic features, have a higher 30 -day mortality rate $(0.6 \%$ vs $2.9 \%$ vs $8.5 \%$, respectively), ${ }^{8}$ thereby supporting the need for routine perioperative troponin surveillance. The ESC and the CCS guidelines recommend that troponin should be measured daily after surgery, for $48-72 \mathrm{~h}$ or until peak, complemented with ECGs to detect ischemia. ${ }^{14,17}$

\section{What Is the Rationale and Evidence for the Management of Patients with MINS?}

Troponin elevation after noncardiac surgery is associated with adverse outcomes. Patients with MINS are also more likely to have known or unknown underlying CAD than patients without MINS. The Coronary CTA VISION Study showed that underlying coronary stenosis was common among patients who had a perioperative MI ( $4 \%$ had normal coronary arteries on Cardiac Computed Tomography Angiography [CTA] and 72\% had obstructive CAD). ${ }^{11}$ Therefore, it is reasonable to consider close monitoring and follow-up with secondary cardiovascular prevention to reduce the risk of subsequent cardiovascular events. The Management of Myocardial Injury After Noncardiac Surgery (MANAGE) $)^{20,21}$ trial was the first randomized controlled trial (RCT) to evaluate treatment strategies in patients with MINS. In MANAGE, 1,754 patients were randomly allocated to receive dabigatran, $110 \mathrm{mg}$ twice-daily, or placebo, from the day of randomization (median of 5 days postoperatively) to the end of 
follow-up (16 months). The primary outcome (a composite of vascular mortality and nonfatal MI, nonhaemorrhagic stroke, peripheral arterial thrombosis, amputation, and symptomatic venous thromboembolism) occured in 97 (11\%) of 877 patients in the dabigatran versus $133(15 \%)$ of 877 patients in the placebo group (HR 0.72; 95\% CI 0.55-0.93; P = 0.0115), with no significant increase in major bleeding ( $\mathrm{HR}=0.92$; $95 \%$ CI: 0.55-1.53). Dabigatran was associated with an increase in minor bleeding ( $15 \%$ with dabigatran vs $10 \%$ with placebo; HR 1.64; CI $95 \% 1.25-2.15$ ). About $60 \%$ of patients were on aspirin and only $3 \%$ were on dual antiplatelet therapy at the time of randomization. There is no RCT on other medications for secondary cardiovascular prevention after perioperative ischemic events. A multivariable prospective analysis of 415 patients with a perioperative MI demonstrated that the initiation of aspirin and statin was associated with a reduction in 30-day mortality (adjusted odds ratio $[\mathrm{aOR}]=0.54 ; 95 \%$ CI: $0.29-0.99$, and aOR $=0.26 ; 95 \%$ CI: $0.13-0.54$, respectively). ${ }^{22} \mathrm{~A}$ case-control study demonstrated that cardiovascular medication intensification (i.e., the introduction of at least 1 among antiplatelets, statin, betablockers, and angiotensin II converting enzyme inhibitors [ACEI]) was associated with a reduction of subsequent cardiovascular events at 1 year for patients who suffered a perioperative MI. ${ }^{23}$ The CCS Guidelines recommend long-term aspirin and statin therapy for patients with MINS. ${ }^{14}$

\section{What Is the Approach to Management of MINS?}

The patient in the abovementioned scenario illustrates that patients with MINS require close follow-up and that MINS might unmask undiagnosed CAD. The following points and Figure 1 summarize our management approach to patients with MINS.

\section{In-hospital:}

1. Assess for high-risk features (persistent chest pain, ST elevation/new LBBB, dynamic ECG changes, or hemodynamic instability). If present, consider inpatient echocardiogram, cardiac catheterization, and cardiology consultation. After the acute phase or among stable patients, further risk stratification with cardiac stress testing can be done while in hospital.

2. Identify nonischemic causes for troponin rise and manage triggers (anemia, tachycardia, hypotension, pulmonary embolism, sepsis, etc.).

3. Implement medications for cardiovascular disease prevention while in hospital including moderateto-high dose statin and aspirin. Consider adding intermediate dose dabigatran. Timing for the initiation of aspirin and the addition of dabigatran should consider bleeding concerns and be discussed with the surgeon.
4. Discuss with the patient about optimal management of cardiovascular risk factors (i.e., lifestyle modification, smoking cessation, BP, and diabetes control if indicated).

\section{Outpatient:}

1. Short-term clinical follow-up within 2-4 weeks whenever possible.

2. Outpatient risk stratification might include noninvasive cardiac testing with stress echocardiography, nuclear stress tests, or coronary CT angiogram. Where available, Positron Emission Tomography scan with flow quantification can be performed, mainly for patients with suspicion of balanced CAD. There are no studies evaluating the benefit of noninvasive stress tests or cardiovascular revascularization in patients with MINS. The clinical expertise of a multidisciplinary team should guide the investigations depending on patients' clinical presentation and preferences.

3. Periodic follow-up, up to 1 year or longer, should be considered, especially in the presence of high-risk features, given the high-risk of cardiovascular events and mortality in the first year.

\section{Perioperative Atrial Fibrillation: Clinical Scenario}

Mrs. M. is a 71-year-old woman undergoing laparotomic resection of a large left ovarian cystic mass (benign pathology). She has hypertension (on amlodipine $10 \mathrm{mg}$ daily), obesity (BMI $38 \mathrm{~kg} / \mathrm{m}^{2}$ ), and obstructive sleep apnea (compliant to CPAP). She does not have any history or symptoms of cardiac disease. Her preoperative NT-proBNP is $550 \mathrm{mg} / \mathrm{L}$. Intraoperatively, her systolic BP was $85 \mathrm{mmHg}$ for $5 \mathrm{~min}$, which improved with intravenous fluids. After surgery, because of the intraoperative hypotension and elevated preoperative NT-proBNP, the anesthetist recommended cardiac monitoring. On postoperative day 1 , the monitor shows atrial fibrillation (AF) with a ventricular rate of 130-140 beats/ min. She is asymptomatic; her BP and oxygen saturation is normal. She receives one dose of intravenous metoprolol; $5 \mathrm{mg}$. Rate control is achieved followed by spontaneous conversion to sinus rhythm the next day. She is worked up for persistently high white blood cell count and a urine culture is positive for E. Coli. After treatment of the urinary tract infection and postoperative cardiac monitoring for 5 days, she is discharged with a scheduled follow-up with surgery and perioperative medicine.

\section{What Is POAF and How Frequent Is It done in Noncardiac Surgery?}

$\mathrm{AF}$ is the most common sustained cardiac arrhythmia in nonsurgical adult populations. POAF comprises AF occurring during an ongoing surgery or in the immediate postoperative 


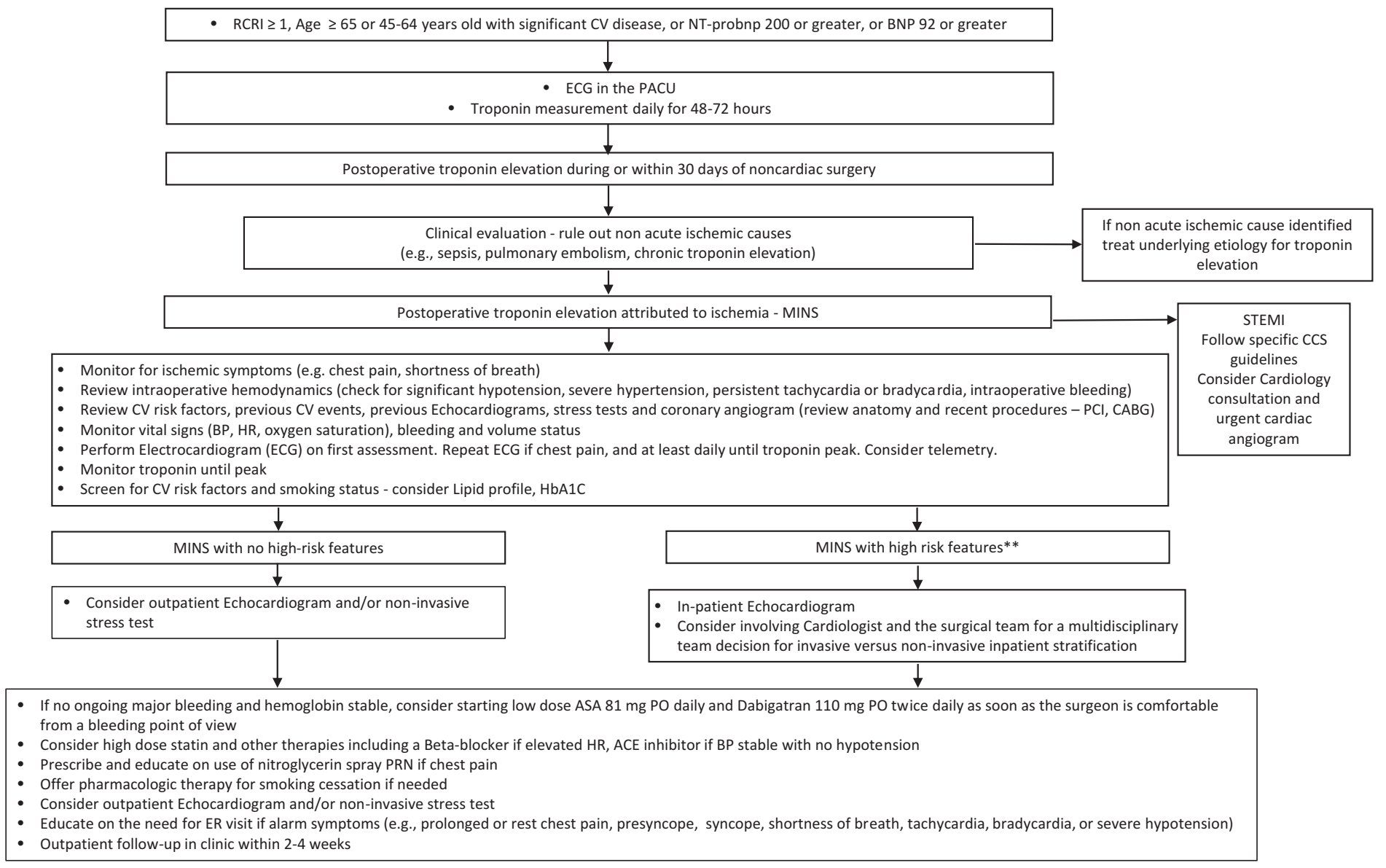

Figure 1. Algorithm on how to manage patients with myocardial injury after noncardiac surgery (MINS).

* NT-proBNP $\geq 200 \mathrm{mg} / \mathrm{L}$ suggested threshold according to Duceppe E, Patel A, Chan M, et al. Preoperative N-Terminal Pro-B-Type Natriuretic Peptide and Cardiovascular Events After Noncardiac Surgery: A Cohort Study. Annals of Internal Medicine 2020; 172:96-104. ${ }^{* *}$ Known high-risk anatomy, persistent chest pain, signs of CHF, ECG with high risk ischemic findings, hemodynamic instability. Abbreviations: ACE: Angiotensin-converting enzyme; ASA: aspirin; BP: blood pressure; CABG: coronary artery bupass graft; CCS: Canadian Cardiovascular Society; CHF: congestive herat failure; CV: cardiovascular; ER: emergency room; HR: heart rare; NT-pro-BNP: N-terminal prohormone of brain natriuretic peptide; PCl: percutaneous coronary intervention; PO: per oral; STEMI: ST elevation MI.

period. While patients with known AF (permanent or paroxysmal) might experience $\mathrm{AF}$ in the perioperative setting, in this review we refer to POAF as new onset, if not otherwise specified. After cardiac surgery, $20-50 \%$ of patients develop POAF ${ }^{24}$; the incidence of POAF after noncardiac thoracic surgery can also be as high as $30 \%$, depending on the type of, and the reason for, the procedure. ${ }^{25}$ The reported incidence of POAF in noncardiac, nonthoracic surgery ranges between $<1$ and $>20 \%$, with higher estimates in abdominal surgery (>10\%) than in total joint replacements (5\%). The average incidence in the largest nonselected noncardiac surgery cohorts is $3 \% .{ }^{26-28}$ POAF typically occurs during the first 4 postoperative days. However, true incidence and time distribution of POAF is likely underestimated, as continuous postoperative ECG monitoring is rarely employed.

\section{Why Does POAF Occur after Noncardiac Surgery?}

The pathophysiology of POAF has not been fully understood, and multiple mechanisms might play a role, including surgery itself, which is associated with the activation of the sympathetic nervous system. Many events in the perioperative period, such as hypotension, hypoxia, hypovolemia or hypervolemia, anemia, metabolic imbalances, trauma, infection, and pain, can also trigger POAF through sympathetic activation or other mechanisms; these factors are more likely to result in POAF in patients with preexistent cardiac disease. ${ }^{29}$ Patient- and surgery-related risk factors that are associated with an increased risk of POAF include older age, male sex, obesity, congestive heart failure, signs of left atrial cardiomyopathy, thoracic surgery, longer procedures, and the use of inotropes. ${ }^{29,30}$ Elevated preoperative BNP or NT-proBNP 
were found to be associated with POAF after thoracic surgery. ${ }^{31,32}$ More recently, in a sub-analysis of the VISION study including 9,789 patients, preoperative NT-proBNP values improved the prediction of POAF risk over conventional prognostic factors across different noncardiac surgeries. Compared with a reference NT-proBNP measurement set at $100 \mathrm{ng} / \mathrm{L}$, adjusted ORs for the occurrence of POAF were 1.31 (95\% CI 1.15-1.49) at 200 $\mathrm{ng} / \mathrm{L}, 2.07$ (95\% CI 1.27-3.36) at $1500 \mathrm{ng} / \mathrm{L}$, and 2.39 (95\% CI $1.26-4.51)$ at $3000 \mathrm{ng} / \mathrm{L} .{ }^{33}$

\section{What Is the Clinical Relevance of POAF?}

Most patients with POAF convert to sinus rhythm spontaneously and many POAF episodes are asymptomatic and remain undetected. However, POAF can also result in hemodynamic instability that requires immediate intervention. POAF has been associated with prolonged hospital stay and an increased risk of perioperative complications, including infections, stroke, and in-hospital mortality. ${ }^{27,34-36}$

POAF that occurs after cardiac surgery is associated with a fivefold increased risk for recurrent AF in the next 5-6 years. ${ }^{37,38}$ By comparison, the risk of recurrent $\mathrm{AF}$ after noncardiac surgery is less studied but is likely to be similar after a long-term follow-up. ${ }^{39}$ Patients who develop POAF after noncardiac surgery are at an increased risk for stroke, death, and other cardiovascular events at 1 year after surgery. ${ }^{40-43}$ A post hoc analysis combined data from the PeriOperative ISchemic Evaluation POISE- $1^{44}$ and POISE-2 trials ${ }^{45,46}$ and included 18,117 patients (mean age 69 years, $57.4 \%$ male) with, or at risk of, cardiovascular disease who were undergoing noncardiac surgery and were not in AF at the time of study enrollment. Compared to those without POAF, patients with POAF had a higher incidence of stroke 1 year after surgery ( 5.58 vs. 1.54 per 100 patient years; $\mathrm{aHR}=$ 3.43; 95\% CI: 2.00-5.90). ${ }^{40}$ POAF was associated with increased mortality (incidence 31.4 vs. 9.3 ; $\mathrm{aHR}=2.5$; $95 \% \mathrm{CI}$ : $2.01-3.14$ ) and $\mathrm{MI}$ (incidence 26.2 vs. 8.23 ; aHR = 5.10; 95\% CI: 3.91-6.64) at 1 year. The long-term incidences of these adverse events are comparable to those of patients clinically diagnosed with AF in nonsurgical contexts. ${ }^{30}$

It is still to be determined whether POAF of different durations or timing of onset, and POAF clinically diagnosed versus detected by continuous ECG monitoring, have a different prognostic value. However, overall, the existing evidence underlines the clinical significance of POAF as a perioperative event with short- and long-term impacts.

\section{How Can POAF be Prevented?}

Existing evidence on perioperative pharmacological strategies to prevent POAF is not definitive. Perioperative beta-blockers have been shown to reduce POAF in noncardiac surgery ${ }^{47}$; however, in the POISE-1 trial, metoprolol increased the incidence of death and stroke 30 days after surgery. ${ }^{44}$ Amiodarone has been showed to be effective, ${ }^{47}$ with lower cumulative doses likely to have a better profile in terms of side effects. ${ }^{48}$ Evidence on perioperative statin and POAF prevention is less robust. ${ }^{47,49}$ Perioperative colchicine to prevent POAF in thoracic surgery is currently under investigation (NCT03310125). Currently, there is no perioperative pharmacological prophylaxis for POAF recommended for every patient undergoing noncardiac surgery; a personalized approach based on a cautious consideration of surgery-related and patient-related risk factors is instead recommended. ${ }^{48}$ Overall, it is reasonable to expect that hemodynamics and laboratory monitoring, in order to prevent or detect early and manage possible triggers, will prevent POAF.

\section{How Should POAF be Acutely Managed?}

POAF should be acutely managed based on the same principles of acute AF management in other contexts, adapted to patient characteristics, patient preferences, and local protocols. ${ }^{30,48}$ In many cases, the rhythm disturbance will resolve with the resolution of the precipitating trigger(s). ${ }^{29}$ In hemodynamically unstable patients, emergency electrical cardioversion is indicated. There are no RCTs done in patients with POAF comparing rate versus rhythm control, or different strategies for rate or rhythm control. Given the high rate of spontaneous conversion to sinus rhythm in POAF, it is reasonable to consider rhythm control only when the patient is symptomatic, and/or when rate control is difficult to achieve..$^{48}$ In the case of nonemergency cardioversion, periprocedural anticoagulation is recommended with the same rules as in AF diagnosed in a nonoperative setting. ${ }^{48}$ Rate control (target heart rate $<100$ beats $/ \mathrm{min}$ ) could be achieved with beta-blockers (preferable in case of known CAD or reduced ejection fraction), nondihydropyridine calcium channel blockers, or digoxin. ${ }^{48}$ In patients with preexisting $\mathrm{AF}$, or at high risk of POAF, we suggest telemetry monitoring at least for the first $24-48 \mathrm{~h}$ after surgery to detect episodes of $\mathrm{AF}$ at risk of hemodynamic compromise and to intervene in a timely fashion (Figure 2).

\section{Should Patients with POAF Receive Long-Term Anticoagulation?}

The adoption of long-term oral anticoagulation (OAC) remains controversial. The high long-term risk of stroke after POAF, like that associated with nonoperative AF, suggests that patients with POAF could benefit from long-term OAC. In a large Danish cohort study, long-term benefit of OAC, initiated within 30 days from discharge, was similar between patients with POAF after noncardiac surgery (HR 0.52; 95\% CI 0.40-0.67) and matched patients diagnosed with nonoperative AF (HR 0.56; 95\% CI 0.51-0.62)..$^{50}$ OAC therapy during follow-up was also associated with a significantly lower risk of all-cause mortality 


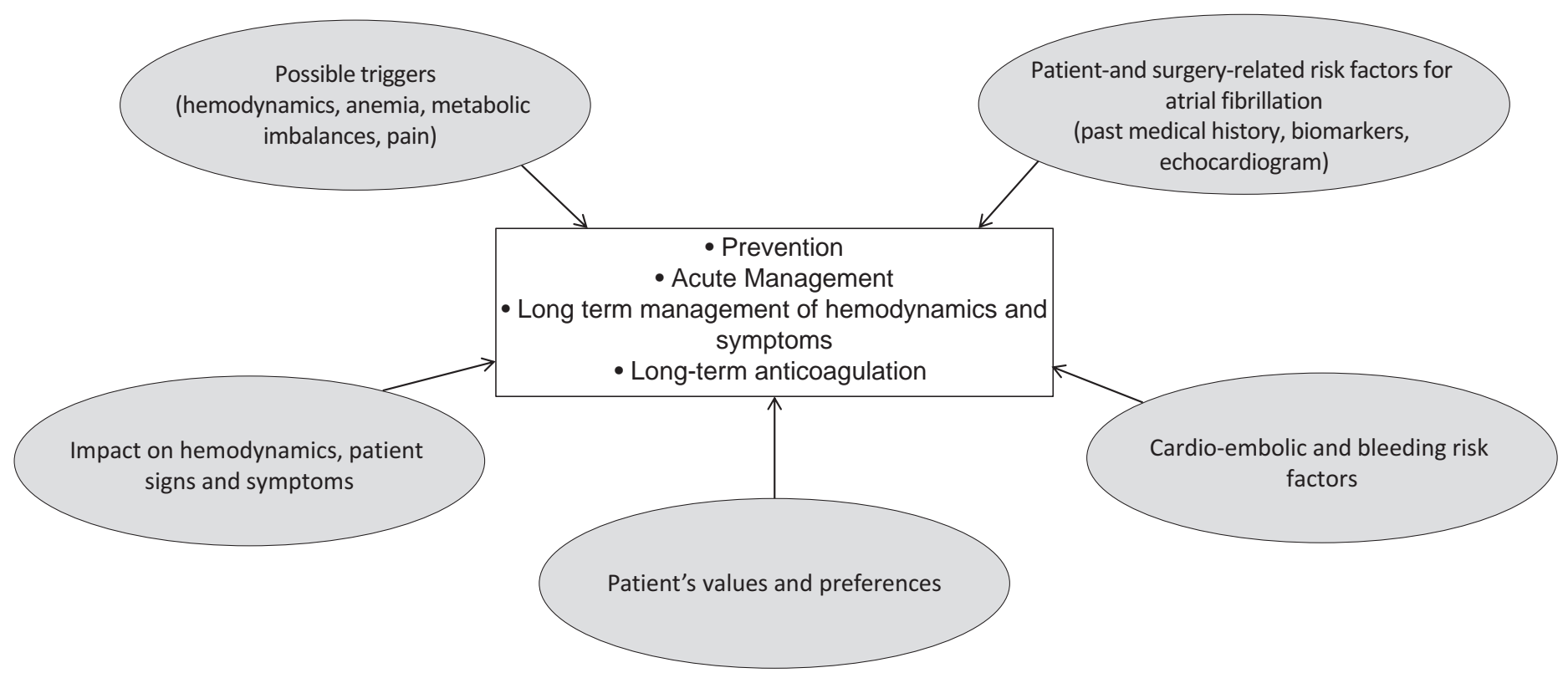

Figure 2. Factors and strategies to consider in the management of perioperative atrial fibrillation (POAF).

in both patients with POAF and nonoperative AF. Alternatively, another large retrospective cohort study, using data from the Quebec Hospital Discharge Database, did not show similar benefits. ${ }^{51}$ Overall, cautious interpretation is needed given the observational nature of this evidence. The ongoing ASPIRE-AF (NCT03968393) randomized trial will inform the long-term benefits and risks of OAC in POAF after noncardiac surgery. In the meantime, current guidelines suggest that long-term OAC therapy should be considered in patients at risk for stroke with POAF after noncardiac surgery, accounting for the anticipated net clinical benefit of OAC therapy and informed patient preferences. ${ }^{48}$ Neither $\mathrm{CHADS}_{2}$ nor the $\mathrm{CHA}_{2} \mathrm{DS}_{2}$-VASc score (congestive heart failure, hypertension, age $\geq 75$ years, diabetes mellitus, stroke/transient ischemic attack, vascular disease, age $65-75$ years, and sex $)^{52,53}$ has been validated in surgical populations, but their use for long-term stroke risk prediction in patients with POAF seems reasonable. ${ }^{29,54} \mathrm{We}$ suggest performing an echocardiogram to evaluate the presence of structural or functional abnormalities that could increase the risk of recurrences and/or of cardioembolic events. In most of the cases, the echocardiogram can be performed in the outpatient setting, unless the patient in-hospital course suggests otherwise (e.g., POAF associated with hemodynamic instability, symptoms of congestive heart failure, or significant myocardial ischemia). Knowing that the patient is having arrhythmia recurrences, even if asymptomatic, through extended ECG Holter monitoring (i.e., 14 days), once the patient is discharged, can also help with the decision about OAC. Patient baseline bleeding risk should also play an important role in the decision. Bleeding risk scores (e.g., HAS-BLED) developed in the nonoperative setting ${ }^{55}$ have not been specifically validated in the setting of initiating OAC for AF diagnosed in the perioperative setting; however, they can provide a reasonable guidance on the long-term risk of bleeding with OAC. In the specific case of POAF, considerations about the bleeding risk related to the type and reason of the recent surgery should be discussed with the surgeon, in relation to the timing of OAC initiation.

\section{How Do We Manage Our Clinical POAF Case?}

Mrs M. is seen by the perioperative medicine service at 1 month after surgery. She reports to be asymptomatic since discharge. In clinic, BP is $165 / 88 \mathrm{mmHg}$, heart rate is 88 beats/ min (regular), and oxygen saturation is $94 \%$ on room air. ECG shows sinus rhythm. Echocardiogram shows mild concentric left ventricular hypertrophy; preserved global and regional left ventricular contractility (ejection fraction 55\%); indeterminate diastolic filling pattern; both atria are moderately dilated; and no valve disease is seen. Although ongoing infection and the intraoperative hypotension were possible triggers of the episode of POAF, she presents predisposing clinical characteristics (obesity, hypertension, cardiac remodelling, and enlarged left atrium), which could also increase the risk of AF recurrences. Her $\mathrm{CHA}_{2} \mathrm{DS}_{2}$-VASc score is 3 (3.2\% risk of stroke per year). Long-term OAC is started in agreement with the patient after discussing potential benefits of stroke prevention and bleeding risk (HAS-BLED score 2 points; $1.88-3.2 \%$ risk of major bleeding 
per year). Initiation of ACE inhibitor, optimal BP control, and weight reduction is also recommended.

\section{Disclosures}

All authors declare no competing interests.

\section{Funding Statement}

Dr. Flavia Kessler Borges holds a McMaster University Department of Medicine Career Research Award. Dr Sandra Ofori holds a Michael G. DeGroote Fellowship Award for Clinical Research. Dr. Maura Marcucci holds a McMaster University Department of Medicine Career Research Award and a PSI Foundation MidCareer Clinical Research Award.

\section{References}

1. Weiser TG, Haynes AB, Molina G, et al. Estimate of the global volume of surgery in 2012: An assessment supporting improved health outcomes. Lancet. 2015;385(Suppl 2):S11. http://dx.doi.org/10.1016/ S0140-6736(15)60806-6

2. Devereaux PJ, Sessler DI. Cardiac complications in patients undergoing major noncardiac surgery. N Engl J Med. 2015;373:2258-69. http://dx.doi. org/10.1056/NEJMra1502824

3. Devereaux P, Xavier D, Pogue J, et al. Characteristics and short-term prognosis of perioperative myocardial infarction in patients undergoing noncardiac surgery. Ann Intern Med. 2011;154:523-8. http://dx.doi. org/10.7326/0003-4819-154-8-201104190-00003

4. Thygesen K, Alpert JS, Jaffe AS, et al. Fourth universal definition of myocardial infarction (2018). Circulation. 2018;138:e618-e51. http://dx.doi. org/10.1161/CIR.0000000000000617

5. Botto F, Alonso-Coello P, Chan MT, et al. Myocardial injury after noncardiac surgery: A large, international, prospective cohort study establishing diagnostic criteria, characteristics, predictors, and 30-day outcomes. Anesthesiology. 2014;120:564-78. http://dx.doi.org/10.1097/ ALN.0000000000000113

6. Puelacher C, Lurati Buse G, Seeberger D, et al. Perioperative myocardial injury after non- cardiac surgery: Incidence, mortality, and characterization. Circulation. 2018;137:1221-32. http://dx.doi.org/10.1161/ CIRCULATIONAHA.117.030114

7. Smilowitz NR, Redel-Traub G, Hausvater A, Armanious A, Nicholson J, Puelacher C, et al. Myocardial injury after noncardiac surgery: A systematic review and meta-analysis. Cardiol Rev. 2019;27(6):267-73. http://dx.doi. org/10.1097/CRD.0000000000000254

8. Devereaux PJ, Biccard BM, Sigamani A, et al. Association of postoperative high-sensitivity troponin levels with myocardial injury and 30-day mortality among patients undergoing noncardiac surgery. JAMA. 2017;317:1642-51. http://dx.doi.org/10.1001/jama.2017.4360

9. Duceppe E, Borges FK, Tiboni M, Pearse R, Chan MTV, Srinathan S, et al. Association between high-sensitivity troponin I and major cardiovascular events after non-cardiac surgery. J Am Coll Cardiol. 2020 Mar;75(11 Suppl. 1):110. http://dx.doi.org/10.1016/S0735-1097(20)30737-3

10. Borges FK, Duceppe E, Heels-Ansdell D, Ofori SN, Marcucci M, Kavsak PA, et al. High-sensitivity troponin I predicts major cardiovascular events after noncardiac surgery. ESC Congress-The Digital Experience. 2020. http:// dx.doi.org/10.1093/ehjci/ehaa946.1675

11. Sheth T, Chan M, Butler C, et al. Prognostic capabilities of coronary computed tomographic angiography before non-cardiac surgery: Prospective cohort study. BMJ (Clinical research ed). 2015;350:h1907. http://dx.doi. org/10.1136/bmj.h1907

12. Gualandro DM, Campos CA, Calderaro D, et al. Coronary plaque rupture in patients with myocardial infarction after noncardiac surgery: Frequent and dangerous. Atherosclerosis. 2012;222:191-5. http://dx.doi.org/10.1016/j. atherosclerosis.2012.02.021

13. Parashar A, Agarwal S, Krishnaswamy A, et al. Percutaneous intervention for myocardial infarction after noncardiac surgery: Patient characteristics and outcomes. J Am Coll Cardiol. 2016;68:329-38. http://dx.doi.org/10.1016/j. jacc.2016.03.602

14. Duceppe E, Parlow J, MacDonald P, et al. Canadian cardiovascular society guidelines on perioperative cardiac risk assessment and management for patients who undergo noncardiac surgery. Can J Cardiol. 2017;33(1):17-32. http://dx.doi.org/10.1016/j.cjca.2016.09.008

15. Lee TH, Marcantonio ER, Mangione CM, et al. Derivation and prospective validation of a simple index for prediction of cardiac risk of major noncardiac surgery. Circulation. 1999 Sep 7;100(10):1043-9. http://dx.doi. org/10.1161/01.cir.100.10.1043

16. Duceppe E, Patel A, Chan M, et al. Preoperative N-terminal pro-B-type natriuretic peptide and cardiovascular events after noncardiac surgery: A cohort study. Ann Intern Med. 2020;172:96-104. http://dx.doi.org/10.7326/ M19-2501

17. The Joint Task Force on non-cardiac surgery: Cardiovascular assessment and management of the European Society of Cardiology (ESC) and the European Society of Anaesthesiology (ESA) 2014 ESC/ESA Guidelines on non-cardiac surgery: Cardiovascular assessment and management. Eur Heart J. 2014;35:2383-431. http://dx.doi.org/10.1093/eurheartj/ehu282

18. De Hert S, Staender S, Fritsch G, et al. Pre-operative evaluation of adults undergoing elective noncardiac surgery. Eur J Anaesthesiol. 2018;35(6):40765. http://dx.doi.org/10.1097/EJA.0000000000000817

19. Thygesen K, Alpert J, Jaffe A, et al. Fourth universal definition of MI. JACC. 2018;72(18):2231-64. http://dx.doi.org/10.1016/j.jacc.2018.08.1038

20. Duceppe E, Yusuf S, Tandon V, et al. Design of a randomized placebocontrolled trial to assess dabigatran and omeprazole in patients with myocardial injury after noncardiac surgery (MANAGE). Can J Cardiol. 2018;34:295-302. http://dx.doi.org/10.1016/j.cjca.2018.01.020

21. Devereaux PJ, Duceppe E, Guyatt G, et al. Dabigatran in patients with myocardial injury after non-cardiac surgery (MANAGE): An international, randomised, placebo-controlled trial. Lancet (London, England). 2018;391:2325-34. http://dx.doi.org/10.1016/S0140-6736(18)30832-8

22. Devereaux PJ, Xavier D, Pogue J, et al. Characteristics and short-term prognosis of perioperative myocardial infarction in patients undergoing noncardiac surgery: A cohort study. Ann Intern Med. 2011;154:523-8. http:// dx.doi.org/10.7326/0003-4819-154-8-201104190-00003

23. Foucrier A, Rodseth R, Aissaoui M, et al. The long-term impact of early cardiovascular therapy intensification for postoperative troponin elevation after major vascular surgery. Anesth Analg. 2014;119:1053-63. http://dx.doi. org/10.1213/ANE.0000000000000302

24. Echahidi N, Pibarot P, O’Hara G, Mathieu P. Mechanisms, prevention, and treatment of atrial fibrillation after cardiac surgery. J Am Coll Cardiol. 2008;51(8):793-801. http://dx.doi.org/10.1016/j.jacc.2007.10.043

25. Amar D. Prevention and management of perioperative arrhythmias in the thoracic surgical population. Anesthesiol Clin. 2008;26(2):325-35, vii. http:// dx.doi.org/10.1016/j.anclin.2008.01.001

26. Joshi KK, Tiru M, Chin T, Fox MT, Stefan MS. Postoperative atrial fibrillation in patients undergoing non-cardiac non-thoracic surgery: A practical approach for the hospitalist. Hosp Pract. 2015;43(4):235-44. http://dx.doi.org /10.1080/21548331.2015.1096181

27. Bhave PD, Goldman LE, Vittinghoff E, Maselli J, Auerbach A. Incidence, predictors, and outcomes associated with postoperative atrial fibrillation after major noncardiac surgery. Am Heart J. 2012;164(6):918-24. http://dx.doi. org/10.1016/j.ahj.2012.09.004

28. Chebbout R, Heywood EG, Drake TM, Wild JRL, Lee J, Wilson M, et al. A systematic review of the incidence of and risk factors for postoperative atrial fibrillation following general surgery. Anaesthesia. 2018;73(4):490-8. http:// dx.doi.org/10.1111/anae.14118

29. Bessissow A, Khan J, Devereaux PJ, Alvarez-Garcia J, Alonso-Coello P. Postoperative atrial fibrillation in non-cardiac and cardiac surgery: An 
overview. J Thromb Haemost. 2015;13(Suppl 1):S304-12. http://dx.doi. org/10.1111/jth.12974

30. Kotecha D, Castella M. Is it time to treat post-operative atrial fibrillation just like regular atrial fibrillation? Eur Heart J. 2020;41(5):652-4a. http://dx.doi. org/10.1093/eurheartj/ehz412

31. Toufektzian L, Zisis C, Balaka C, Roussakis A. Effectiveness of brain natriuretic peptide in predicting postoperative atrial fibrillation in patients undergoing non-cardiac thoracic surgery. Interact Cardiovasc Thorac Surg. 2015;20(5):654-7. http://dx.doi.org/10.1093/icvts/ivu454

32. Simmers D, Potgieter D, Ryan L, Fahrner R, Rodseth RN. The use of preoperative B-type natriuretic peptide as a predictor of atrial fibrillation after thoracic surgery: Systematic review and meta-analysis. J Cardiothorac Vasc Anesth. 2015;29(2):389-95. http://dx.doi.org/10.1053/j.jvca.2014.05.015

33. Szczeklik W, LeManach Y, Fronczek J, et al. Preoperative levels of natriuretic peptides and the incidence of postoperative atrial fibrillation after noncardiac surgery: A prospective cohort study. CMAJ. 2020;192:E1715-22. http:// dx.doi.org/10.1503/cmaj.200840

34. Polanczyk CA, Goldman L, Marcantonio ER, Orav EJ, Lee TH. Supraventricular arrhythmia in patients having noncardiac surgery: Clinical correlates and effect on length of stay. Ann Intern Med. 1998;129(4):279-85. http://dx.doi.org/10.7326/0003-4819-129-4-199808150-00003

35. Kanji S, Williamson DR, Yaghchi BM, Albert M, McIntyre L, Canadian Critical Care Trials Group. Epidemiology and management of atrial fibrillation in medical and noncardiac surgical adult intensive care unit patients. J Crit Care. 2012;27(3):326 e1-8. http://dx.doi.org/10.1016/j. jcrc.2011.10.011

36. Christians KK, Wu B, Quebbeman EJ, Brasel KJ. Postoperative atrial fibrillation in noncardiothoracic surgical patients. Am J Surg. 2001;182(6):713-15. http://dx.doi.org/10.1016/S0002-9610(01)00799-1

37. Konstantino Y, Zelnik Yovel D, Friger MD, Sahar G, Knyazer B, Amit G. Postoperative atrial fibrillation following coronary artery bypass graft surgery predicts long-term atrial fibrillation and stroke. Isr Med Assoc J. 2016;18(12):744-8.

38. Ahlsson A, Fengsrud E, Bodin L, Englund A. Postoperative atrial fibrillation in patients undergoing aortocoronary bypass surgery carries an eightfold risk of future atrial fibrillation and a doubled cardiovascular mortality. Eur J Cardiothorac Surg. 2010;37(6):1353-9. http://dx.doi.org/10.1016/j. ejcts.2009.12.033

39. Ayoub K, Habash F, Almomani A, Xu J, Marji M, Shaw-Devine A, et al. Long term risk of recurrent atrial fibrillation and ischemic stroke after postoperative atrial fibrillation complicating cardiac and non-cardiac surgeries. J Atr Fibrillation. 2018;10(6):1660. http://dx.doi.org/10.4022/jafib.1660

40. Conen D, Alonso-Coello P, Douketis J, Chan MTV, Kurz A, Sigaman A, et al. Risk of stroke and other adverse outcomes in patients with perioperative atrial fibrillation 1 year after non-cardiac surgery. Eur Heart J. 2020;41(5):645-51. http://dx.doi.org/10.1093/eurheartj/ehz431

41. Gialdini G, Nearing K, Bhave PD, Bonuccelli U, Iadecola C, Healey JS, et al. Perioperative atrial fibrillation and the long-term risk of ischemic stroke. JAMA. 2014;312(6):616-22. http://dx.doi.org/10.1001/jama.2014.9143

42. Lin MH, Kamel H, Singer DE, Wu YL, Lee M, Ovbiagele B. Perioperative/ postoperative atrial fibrillation and risk of subsequent stroke and/ or mortality. Stroke. 2019;50(6):1364-71. http://dx.doi.org/10.1161/ STROKEAHA.118.023921
43. AlTurki A, Marafi M, Proietti R, Cardinale D, Blackwell R, Dorian P, et al. Major adverse cardiovascular events associated with postoperative atrial fibrillation after noncardiac surgery: A systematic review and metaanalysis. Circ Arrhythm Electrophysiol. 2020;13(1):e007437. http://dx.doi. org/10.1161/CIRCEP.119.007437

44. Devereaux PJ, Yang H, Yusuf S, Guyatt G, Leslie K, Villar JC, et al. Effects of extended-release metoprolol succinate in patients undergoing noncardiac surgery (POISE trial): A randomised controlled trial. Lancet. 2008;371(9627):1839-47. http://dx.doi.org/10.1016/S0140-6736(08)60601-7

45. Devereaux PJ, Mrkobrada M, Sessler DI, Leslie K, Alonso-Coello P, Kurz A, et al. Aspirin in patients undergoing noncardiac surgery. $\mathrm{N}$ Engl J Med. 2014;370(16):1494-503. http://dx.doi.org/10.1056/NEJMoa1401105

46. Devereaux PJ, Sessler DI, Leslie K, Kurz A, Mrkobrada M, Alonso-Coello P, et al. Clonidine in patients undergoing noncardiac surgery. N Engl J Med. 2014;370(16):1504-13. http://dx.doi.org/10.1056/NEJMoa1401106

47. Oesterle A, Weber B, Tung R, Choudhry NK, Singh JP, Upadhyay GA. Preventing postoperative atrial fibrillation after noncardiac surgery: A metaanalysis. Am J Med. 2018;131(7):795-804.e5. http://dx.doi.org/10.1016/j. amjmed.2018.01.032

48. Hindricks G, Potpara T, Dagres N, Arbelo E, Bax JJ, Blomstrom-Lundqvist C, et al. 2020 ESC Guidelines for the diagnosis and management of atrial fibrillation developed in collaboration with the European Association of Cardio-Thoracic Surgery (EACTS). Eur Heart J. 2020.

49. Chopra V, Wesorick DH, Sussman JB, Greene T, Rogers M, Froehlich JB, et al. Effect of perioperative statins on death, myocardial infarction, atrial fibrillation, and length of stay: A systematic review and meta-analysis. Arch Surg. 2012;147(2):181-9. http://dx.doi.org/10.1001/archsurg.2011.897

50. Butt JH, Olesen JB, Havers-Borgersen E, Gundlund A, Andersson C, Gislason $\mathrm{GH}$, et al. Risk of thromboembolism associated with atrial fibrillation following noncardiac surgery. J Am Coll Cardiol. 2018;72(17):2027-36. http://dx.doi.org/10.1016/j.jacc.2018.07.088

51. Ref Elharram M, Samuel M, AlTurki A, et al. Anticoagulant use and the risk of thromboembolism and bleeding in post-operative $\mathrm{AF}$ following non-cardiac surgery. Can J Cardiol. 2020. http://dx.doi.org/10.1016/j. cjca.2020.08.023

52. Gage BF, Waterman AD, Shannon W, Boechler M, Rich MW, Radford MJ. Validation of clinical classification schemes for predicting stroke: Results from the National Registry of Atrial Fibrillation. JAMA. 2001;285(22):286470. http://dx.doi.org/10.1001/jama.285.22.2864

53. Lip GY, Nieuwlaat R, Pisters R, Lane DA, Crijns HJ. Refining clinical risk stratification for predicting stroke and thromboembolism in atrial fibrillation using a novel risk factor-based approach: The euro heart survey on atrial fibrillation. Chest. 2010;137(2):263-72. http://dx.doi.org/10.1378/ chest.09-1584

54. Danelich IM, Lose JM, Wright SS, Asirvatham SJ, Ballinger BA, Larson DW, et al. Practical management of postoperative atrial fibrillation after noncardiac surgery. J Am Coll Surg. 2014;219(4):831-41. http://dx.doi. org/10.1016/j.jamcollsurg.2014.02.038

55. Zeng J, Yu P, Cui W, Wang X, Ma J, Zeng C. Comparison of HAS-BLED with other risk models for predicting the bleeding risk in anticoagulated patients with atrial fibrillation: A PRISMA-compliant article. Medicine (Baltimore). 2020 Jun 19;99(25):e20782. http://dx.doi.org/10.1097/MD.0000000000020782 